\title{
Impaired inflammatory state of the endometrium: a multifaceted approach to endometrial inflammation. Current insights and future directions
}

\author{
Amal Drizi ${ }^{1}$, Dusan Djokovic ${ }^{2,3}$, Antonio Simone Laganà ${ }^{4}$, Bruno van Herendael ${ }^{5}$ \\ ${ }^{1}$ Independent consultant in Obstetrics and Gynecology, Algiers, Algeria \\ 2Department of Obstetrics and Gynecology, Nova Medical School - Faculdade de Ciências Médicas, Nova University of Lisbon, \\ Lisbon, Portugal \\ ${ }^{3}$ Department of Obstetrics and Gynecology, Hospital S. Francisco Xavier - Centro Hospitalar Lisboa Ocidental, Lisbon, Portugal \\ ${ }^{4}$ Department of Obstetrics and Gynecology, "Filippo Del Ponte" Hospital, University of Insubria, Varese, Italy \\ ${ }^{5}$ Department of Minimally Invasive Gynecologic Surgery, Stuivenberg General Hospital, Antwerp, Belgium
}

\begin{abstract}
New insights into the complex and fine-regulated inflammatory mechanisms involved in the endometrium reveal multiple facets to the problem of endometrial inflammation. However, the entity termed chronic endometritis is to date restricted to infectious etiology and managed with antibiotics. Conversely, the concept of impaired inflammatory state of the endometrium (IISE) provides a more global approach to defective endometrial inflammation, considering both infectious and non-infectious etiology. A non-systematic review was done through a search on MEDLINE, EMBASE, Global Health, The Cochrane Library, Health Technology Assessment Database and Web of Science, research registers. Pertinent original and review articles, published in English or French until December 31, 2019, were selected. A compelling body of evidence demonstrates transient, repeated and persistent IISE to be a major factor of most problematic disorders in obstetrics/gynecology, such as endometrial polyps, unexplained infertility, miscarriage, placenta-related pathology and endometrial cancer. When scheduled accordingly, hysteroscopy can play a key role in the IISE assessment. Robust data suggests the pertinence of minimal-effective anti-inflammatory regimens for therapeutic IISE targeting.

This review provides a comprehensive update on the multiple facets of inflammation in the endometrial physiology and pathology. Further research is needed to improve classification, diagnosis and treatment of IISE.
\end{abstract}

Key words: impaired inflammatory state of the endometrium, chronic endometritis, endometrial polyp, infertility.

\section{Introduction}

Inflammation is a biological reaction to disrupted tissue homeostasis, triggered by any interfering factor [1-4]. The World Health Organization (WHO) considers chronic inflammatory diseases as the greatest burden to human health, affecting any organ of the body and among the major causes of death worldwide [3, 5]. However, its role in the pathogenesis of the reproductive system disorders is still debated [3]. Given the alarming epidemiology of chronic inflammation and the availability of suggestive data, non-microbial inflammation deserves further investigations to clarify whether it plays a key role (at least in part) for obstetric and gynecological disease.

This work aims to review the concept of impaired inflammatory state of the endometrium (IISE) as a multifaceted approach to the problem of endometrial in- flammation, in contrast to the entity termed chronic endometritis (CE), currently restricted to infectious etiology and managed with antibiotics. It gives insights into the endometrial inflammation as a fundamental process, related to infectious and non-infectious factors, and involved both in physiologic and pathogenic conditions in obstetrics and gynecology, such as infertility, endometrial polyps, miscarriage and abnormal placentation-related diseases.

\section{Methods}

A non-systematic review was done through a search on the following databases: MEDLINE, EMBASE, Global Health, The Cochrane Library (Cochrane Database of Systematic Reviews, Cochrane Central Register of Controlled Trials, Cochrane Methodology Register), Health 
Technology Assessment Database and Web of Science, research registers (such as www.cliniclatrials.gov); we used the medical subject heading (MeSH) term Inflammation (MeSH Unique ID: D007249) in combination with: Endometrium (MeSH Unique ID: D004717); Endometritis (MeSH Unique ID: D004716). We selected pertinent original and review articles, published in English or French until 31 December 2019, focusing about CE, endometriosis, endometrial polyps, infertility and placenta-related complications, endometrial inflammation assessment and pharmacological targeting.

\section{General features of the inflammatory response}

Microbial pathogens, but also mechanical trauma, extreme temperatures, ischemia, hypoxia, foreign bodies, pollutants, toxic, irritant, metabolic and allergenic agents are potent activators of the inflammatory response [1-11]. Pathogen-associated molecular patterns (PAMPS) and/or damage-associated molecular patterns (DAMPS) are derived either from pathogens or damaged cells and subsequently recognized by the pattern-recognition-receptors of the host's cells [7-9, 12, 13]. The innate immune system, involving a variety of soluble molecules (cytokines) and immune cells, is first triggered, leading to a cascade of vascular and immune reactions. Subsequently, 4 to 7 days later, the adaptive immune system is eventually involved and consists of a $\mathrm{T}$ or B-cells-mediated specific response against the antigen [10, 14-17]. The return to homeostasis is orchestrated by active pro-resolution pathways, limiting damage to the cells by clearing leukocytes and tissue debris, thus allowing prompt restoration of tissue and vascular functions [18-22] (Fig. 1).

Acute inflammation lasts less than 2 weeks and is characterized by 5 cardinal clinical signs: redness (rubor), heat (calor), edema (tumor), pain (dolor) and loss of function (functio laesa) [17]. Ideally, this results in a restitutio ad intergrum of the tissue. However, inflammation could evolve, after a subacute 2-to-6week phase, to chronicity, displaying different symptoms, as the acute inflammation cardinal signs become mild or absent. These include constant fatigue, sleep disorders, depression, mood disorders, gastrointestinal complaints, weight gain, frequent infections, allergies and body pain [5, 23, 24]. Chronic inflammation is characterized by different cellular, vascular and histological features [5, 23, 24]. Furthermore, various causes and different mechanisms explain its pathogenesis [3, 5, 17, 20, 25-28] (Fig. 2). The challenging

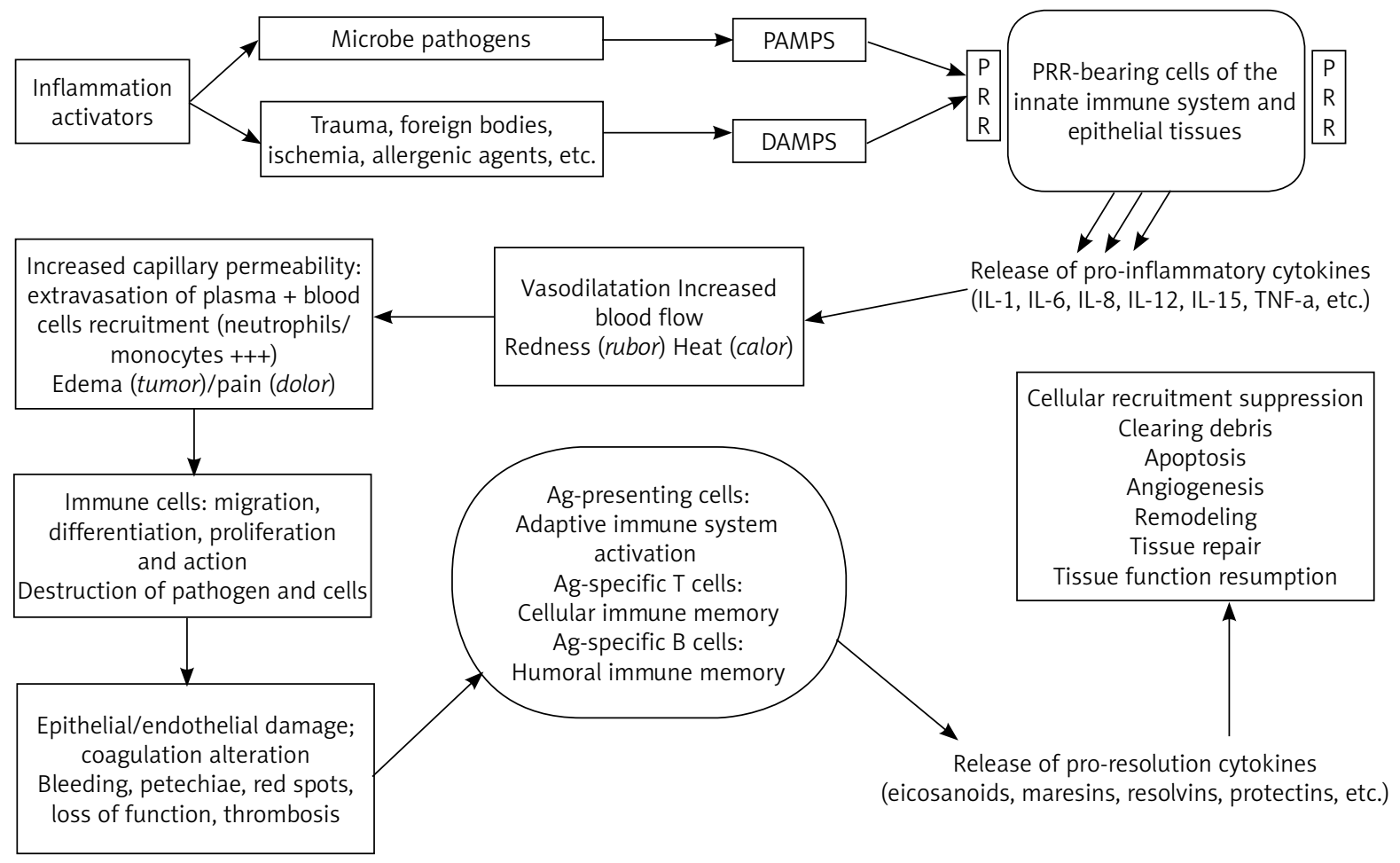

PAMPS - pathogen-associated molecular patterns, DAMPS - damage-associated molecular patterns, PRR - pattern-recognition receptors, IL - interleukin, TNF - tumor necrosis factor, Ag - antigen

Fig. 1. Schematic illustration of acute inflammation orchestrated by the innate and adaptive immune system 


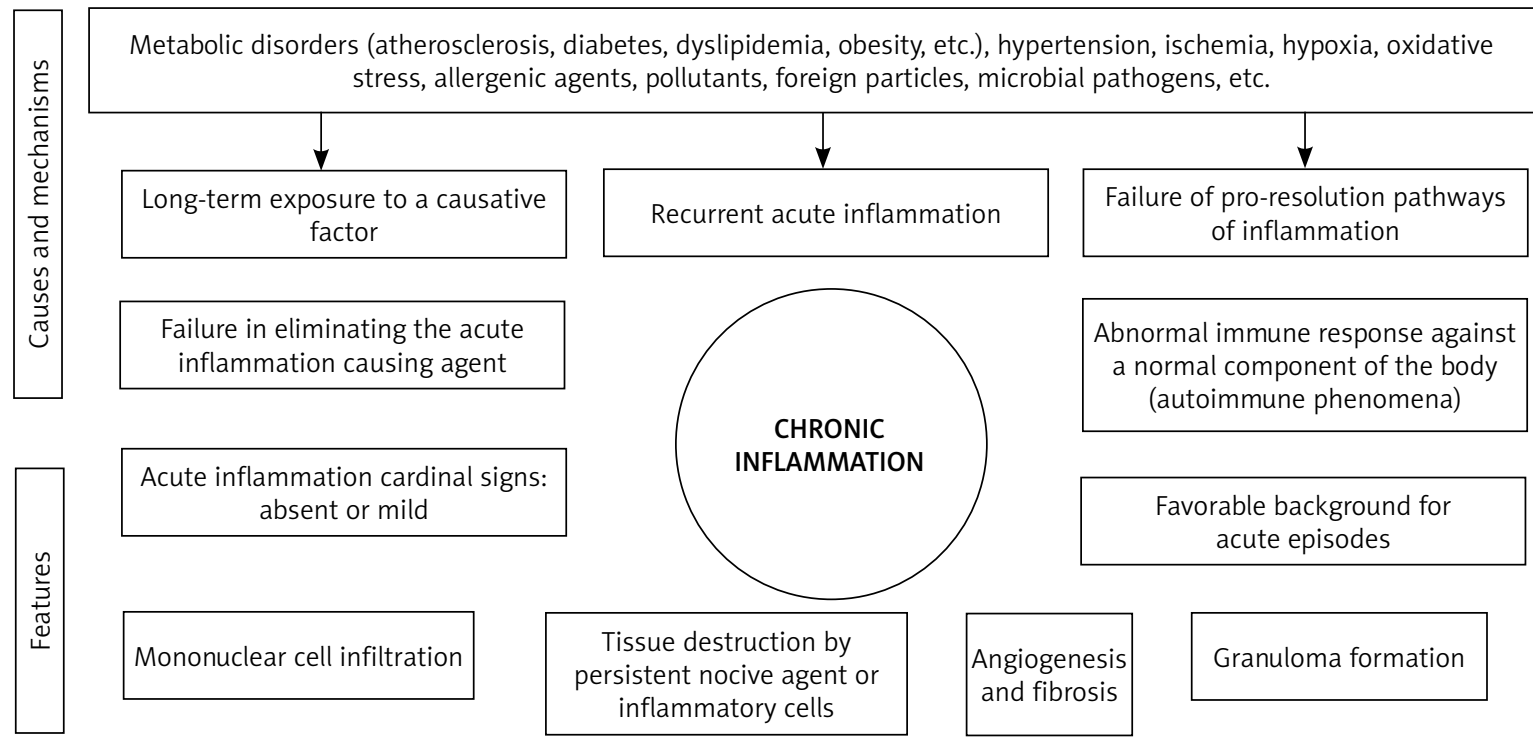

Fig. 2. Causes, mechanisms and features of chronic inflammation

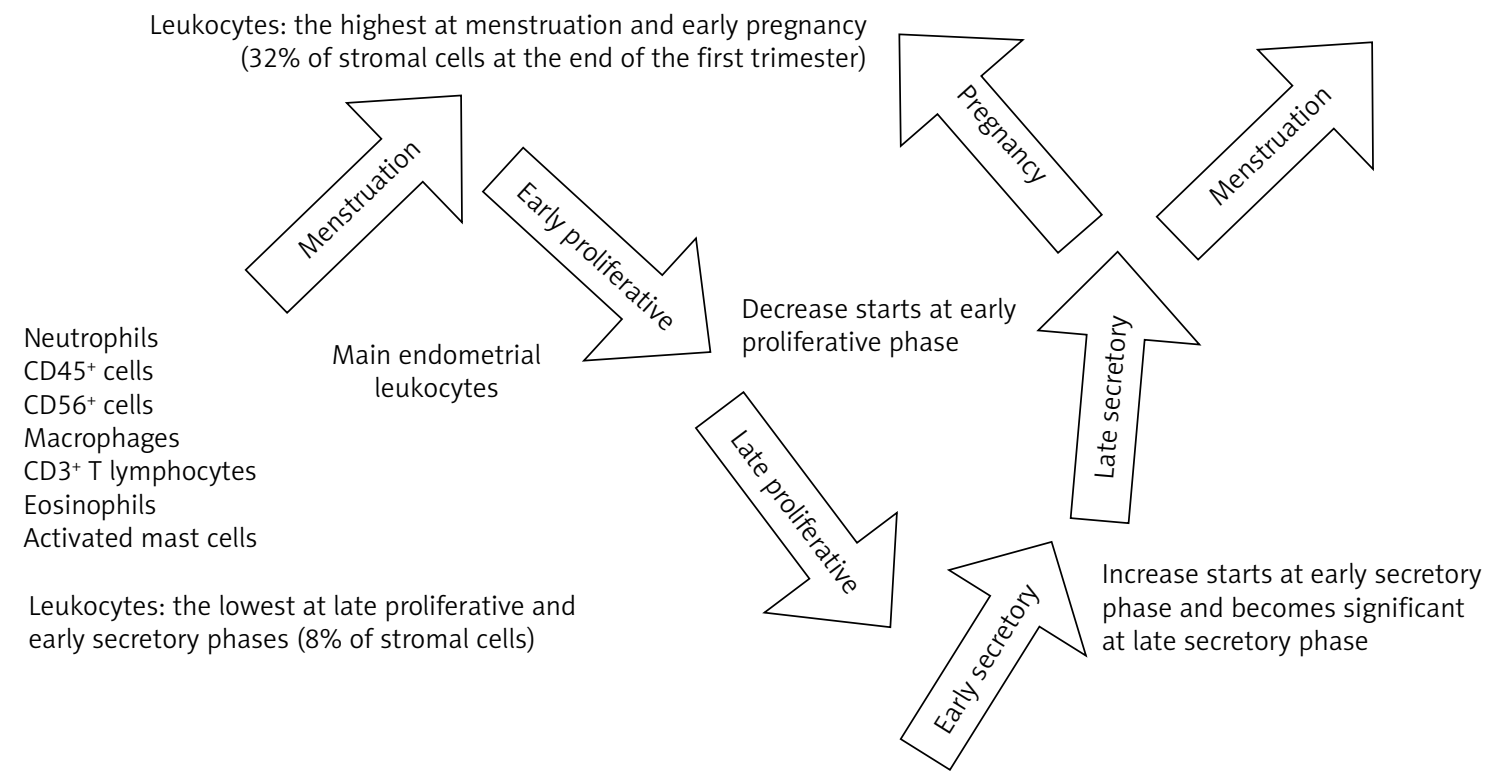

CD45+ cells:

$400 / \mathrm{mm}^{2}$ at proliferative/early secretory up to $1200-1500 / \mathrm{mm}^{2}$ at late secretory phase and menstruation*

CD56 ${ }^{+}$natural killer cells:

$200 / \mathrm{mm}^{2}$ at proliferative/early secretory up to $750-1000 / \mathrm{mm}^{2}$ at late secretory phase and menstruation*

* the mean count $/ \mathrm{mm}^{2}$ of $\mathrm{CD} 45^{+}$and $\mathrm{CD} 56^{+}$endometrial leukocytes

Fig. 3. Time-dependent fluctuations of the main endometrial leukocyte populations throughout the menstrual cycle and early pregnancy

deeper understanding of the inflammatory response in its molecular, humoral, cellular and histopathological aspects should contribute to improved diagnostic and therapeutic strategies of inflammation-mediated pathologies.

\section{The physiological inflammatory state of normal endometrium}

A vast amount of literature acknowledges inflammation as a key mechanism in physiological reproductive events, such as menstruation, ovulation, implantation 
and gestation [3, 17, 23, 29-35]. Endometrial physiology underlies a cyclical injury-healing process, displaying all the hallmarks of a self-limiting inflammation [17, 30]. Leukocytes are scattered in the stroma with aggregations around the glands [36] in a menstrual cycle-dependent fashion: their proportion among stromal cells ranges from $8 \%$ in proliferative endometrium to $32 \%$ in early pregnancy decidua [31]. Neutrophils are the prominent leukocytes during menstruation and start increasing after progesterone withdrawal in late secretory phase [37]. Macrophages, eosinophils and activated mast cells have a similar distribution, yet in smaller proportions [17, 30, 37]. The other main leukocytes of normal endometrium are $\mathrm{CD} 56^{+}$uterine natural killer (UNK) cells which account for $2 \%$ of stromal cells in proliferative endometrium, $17 \%$ during late secretory phase and more than $70 \%$ of endometrial leukocytes at the end of the first trimester of pregnancy where they play a role in trophoblast invasion and increased spiral artery blood flow [31, 33-36, 38, 39]. They are however characterized by gradual decrease of their cytotoxic activity until suppression in late secretory phase and early stage of pregnancy, thus allowing a favorable environment for implantation [33, 40].

Studies have revealed fluctuating time-dependent quantitative and qualitative changes of the recruited leukocytes (Fig. 3), the involved cytokines and the vascular aspects throughout the menstrual cycle and pregnancy $[17,23,30-32,34,36-40]$. The vascular changes mainly consist of vasoconstriction, vasodilatation, increased capillary permeability and angiogenesis. Interleukin (IL)1, IL-6, IL-8 and peptide growth factors are demonstrated to have a key role in reproductive physiology and pathology, mainly via the prostaglandin biosynthetic pathway [17, 39, 41, 42]. Furthermore, studies have demonstrated the key role of active pro-resolution pathways aimed to control inflammation, thus allowing resumption of normal reproductive functions [17, 19-21]. Exacerbated activation of pro-inflammatory pathways and/or failure of pro-resolution pathways have already been described as a cause of reproductive disorders $[17,40]$.

The impact of estradiol and progesterone on inflammation has also been demonstrated as their receptors are expressed in all the cells of the innate and the adaptive immune systems [5, 43-46]. They can suppress the production and secretion of several pro-inflammatory markers, such as IL-6 and IL-1 $\beta[45,46]$. Furthermore, progesterone decreases the cytotoxic activity of uNKcells during secretory phase and pregnancy; and when decreased, it causes activation of some pro-inflammatory mediators and neutrophils recruitment in the endometrium [17, 33, 37, 47].

\section{The concept of impaired inflammatory state of the endometrium}

The delicate balance of pro-inflammatory and pro-resolution mechanisms in normal endometrium is well documented, thus explaining how over-activation of inflammation is as problematic as its suppression $[17,45]$. An objective assessment of "normal endometrial inflammatory state" requires considering the time-changing quantitative and qualitative inflammatory patterns of the endometrium. However, to date this evaluation is totally operator-dependent with a consistent inter-observer variability. The diagnosis should rely on objective scores though, considering the stromal edema, the vascular patterns as well as the distribution and counts of the endometrial inflammatory markers for each reproductive phase. The observation of a "late-secretory-phase-pattern" during proliferative phase, for instance, may indicate an "impaired inflammatory state of the endometrium" (IISE).

IISE is a more appropriate terminology than "endometritis", especially because the latter literally means "inflammation of the endometrium", regardless of its causative factor. Yet, inflammation is already a consistent part of normal endometrium, the term "impaired" is thus more convenient for anomaly.

Depending on the nature of the causative factor and the attenuating circumstances, the IISE is transient, repeated or persistent. A transient IISE is an "out-ofphase" inflammatory disorder caused by any interfering factor. In fact, the monthly chance of pregnancy in the average young and healthy fertile human couple is around 30\% [48]. A transient IISE partially explains this low percentage. If persistent or recurrent, an IISE can have considerable consequences on fertility. It is well established today that repeated acute inflammation is one of the forms of chronic inflammation [5].

However, to date, most acknowledged forms of impaired endometrial inflammation only consider germs or foreign bodies as causative factors. "Acute endometritis", for instance, is defined as an acute response to pathogens. It is characterized by excessive exudation and leukocyte infiltration, predominantly granulocytes [23]. Specific endometritis is characterized by specific granulomatous lesions, such as the foreign body granuloma and the tuberculosis granuloma [5]. Immunological changes are also described in category $\mathrm{E}$ of abnormal uterine bleeding of the International Federation of Gynecology and Obstetrics (FIGO AUB-E), previously denominated dysfunctional uterine bleeding. Among these changes: impaired prostaglandin activity [41, $42,46,47]$, in addition to increased CD56 ${ }^{+}$cells during proliferative and early secretory phases (5\% of stromal cells instead of 2\%) [38].

"Persistent or recurrent IISE" is a more accurate terminology than CE. To date, CE is an anatomo-clinical entity displaying a number of paradoxical features. In fact, histological diagnosis of CE is mainly based on the presence of plasma cells, normally absent or very low in the endometrium [23, 49-54]. Therefore, this definition does not take into consideration the other impaired inflammatory parameters of the endometrium. 

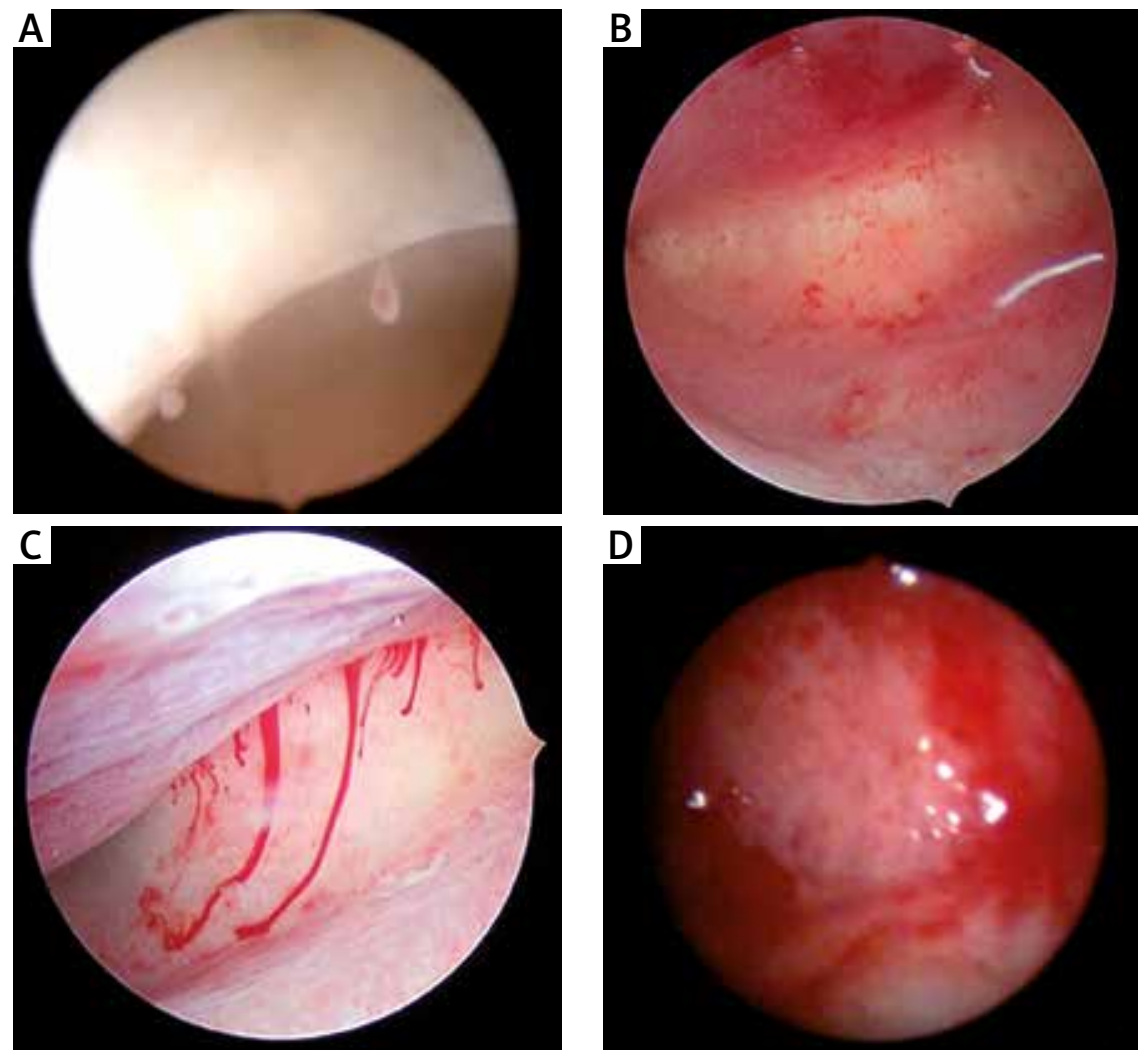

Fig. 4. Hysteroscopic signs of what is termed chronic endometritis. A) micropolyps; B) hyperemia: red spots and petechiae; C) spontaneous bleeding and stromal edema; D) "chronic endometritis-like" redness and edema at day 14 of the menstrual cycle: progestin-only contraception

In addition, hysteroscopic diagnosis of CE is consensually based on the presence of strawberry pattern, focal hyperemia, hemorrhagic spots, micro-polyps and stromal edema [51, 53, 55, 56] (Fig. 4). However, it is well established in immunology that hyperemia and edema are typical cardinal signs for acute inflammation, not the chronic one which is rather silent [5, 24]. The presence of acute inflammation signs can be explained though by the fact that chronic inflammation makes perfect ground for repeated acute episodes. CE has already been histologically demonstrated in patients free of hysteroscopic signs, since negative predictive values range from 83 to $89 \%$, i.e. in about 10 to $20 \%$ of patients with normal hysteroscopy, there was histological evidence of CE [55-57]. Limited observer agreement is a possible explanation. Nonetheless, recent literature concludes that absence of hysteroscopic features does not rule out CE [57]. Conversely, positive predictive values range from 42 to $94 \%$, which is low in most studies [57]. This indicates either a transient IISE, or limited histological diagnostic tools due to the absence of a rigorous definition of endometrial inflammatory patterns.

Furthermore, germs and/or altered microbiota are, to date, the unique cause admitted for chronic inflammation in human endometrium, and exclusively man- aged with antibiotics [35, 49, 53-56, 58-60]. Despite absence of evidence of pathogens in $25 \%$ of women diagnosed for CE [56], and despite hysteroscopic persistence of CE after antibiogram-based antibiotic therapy in $28 \%$ of patients [59], only germs are targeted, and never inflammation as an independent process, nor the other possible causes of impaired inflammation.

Migration of circulating B lymphocytes to the endometrial stromal compartment has been found to be induced by gram-negative bacteria [54]. However, the growing concept of microbiota has demonstrated a potential co-existence between microorganisms and healthy endometrium without causing disease $[50,60]$. Underlying conditions predisposing to impaired endometrial inflammation are susceptible of altering the microenvironment, leading to impaired microbiota or pathogens, thus causing a vicious circle. For that matter, recently published results of a trans-sectional preliminary analysis of an ongoing case-control study [61], evaluated with DNA sequencing the endometrial and vaginal microbiota during the implantation window in patients suffering from repeated implantation failure (RIF) versus control group. Despite limited number of enrolled patients (28 in RIF and 18 in control group), one of the main findings was that endometrial microbiota, and not the vaginal one, showed a marked variance be- 
tween the individuals. One confounding factor claimed to explain it was the different types of cycles (natural, hCG-triggered and hormone replacement cycles).

Regarding non-infectious inflammatory etiology, a higher prevalence of CE was correlated with endometriosis, a history of prolonged menstrual bleeding episodes, infertility, abortion and fallopian tube obstruction $[52,62]$. Furthermore, there is evidence regarding the impact of non-infectious conditions on the endometrial fine-regulated inflammatory balance. In fact, multiple impaired inflammatory mechanisms of the endometrium have been demonstrated in heavy menstrual bleeding, abnormal implantation/placentationrelated issues, such as infertility, recurrent miscarriage, congenital anomalies, stillbirth, preterm delivery, fetal growth restriction and pregnancy-induced hypertension. They consist of increased uNK-cells during proliferative and early secretory phases; higher percentage of uNK-cells expressing activation-antigens; elevated levels of Thelper (Th) 1 cells contrasting with low Th2-cells and over-activation of the prostaglandin inflammatory pathway [33-35, 38-40, 45, 63-67]. There is clear evidence that controlled immune functions play a pivotal role in initiating a normal pregnancy, as they modulate the decidual response, cytokine balance, vascular adaptation, epithelial embryo attachment, trophoblast invasion, placental morphogenesis and also immune tolerance [45]. It is well documented that any disequilibrium in favor of suppressed or excessive inflammation in the endometrium significantly affects fertility or placental morphogenesis, subsequently leading to the above-cited gestational disorders $[45,67]$.

In addition, analysis of the acknowledged risk factors for preeclampsia by the U.S. Preventive Services Task Force guideline [68] shows that most of them are risk factors for chronic inflammation too: age of 35 years or older, body mass index greater than 30, chronic hypertension, type 1 or 2 diabetes, renal disease and autoimmune disease (such as systemic lupus erythematosus and antiphospholipid syndrome).

Metabolic disorders, such as diabetes, dyslipidemia, hypertension and obesity, have been ascertained to over activate the immune system, causing leukocyte activation, with greater numbers of leukocytes with pro-inflammatory phenotypes, thus explaining predisposition to chronic inflammatory diseases $[25,27]$. They are well established risk factors for endometrial cancer too, which is already acknowledged as a chronic inflammation-mediated condition [17, 69, 70]. They are also significantly associated with increased risk of abnormal uterine bleeding, fertility issues as well as miscarriage and stillbirth, with remarkable improvement obtained with stricter metabolic control [71-73].

The oxidative stress, mediated by toxic habits (such as smoking), excessive pollution, allergies, sleep disorders and increasing age, is also demonstrated to pre- dispose to chronic inflammatory state. Correlation with unexplained infertility, spontaneous abortion, recurrent pregnancy loss and preeclampsia has been documented [5, 74-77].

Additionally, the physiological effect of sex hormones on endometrial inflammation may explain both transient and persistent IISE in case of hormonal imbalances [17, 40-44, 78]. The borderline between "hormone-dependent" and "inflammation-mediated" disorder thus becomes blurred, as hormone imbalances induce impaired inflammation. Conversely, the latter alters hormone receptors' expression both in epithelial and stromal cells, thus maintaining a vicious circle [54].

Stress was also demonstrated to induce localized inflammation in the uterus and cause an immune-endocrine disequilibrium involved in infertility, miscarriage, late pregnancy complications and impaired fetal development, mainly via elevated levels of cortisol as well as significant reduction in progesterone levels followed by impaired activity of UNK-cells $[35,78,79]$.

In endometriosis, altered expression of estrogen and progesterone receptors has been associated with resistance to progesterone and over-expression of pro-inflammatory cytokines, such as IL-1, IL-6 and tumor necrosis factor (TNF-). Auto-antibodies against endometrial cells have also been described in endometriosis [32, 35, 63, 80-82]. Recent data found in patients with endometriosis a different behavior of some endometrial immune cells (macrophages, dendritic cells and $T$ cells). The latter display more pro-inflammatory properties, compared to women without the disease $[83,84]$.

In adenomyotic nodules, high levels of inflammatory and neurogenic mediators have been reported [85]. The latter is demonstrated to be correlated with a higher incidence of implantation failure and abnormal placentation-related complications like miscarriage and pregnancy-induced hypertension [64, 86-88].

Auto-immune, allergenic and chronic inflammatory diseases directly interfere with the immune system and are correlated with decreased fertility [11, 25, 28, 35]. Even in the absence of a clinically overt autoimmune disease, anti-phospholipid, anti-thyroid, or antinuclear autoantibodies have been reported to be correlated with implantation failure and early pregnancy loss, especially when associated to vasculitis [65].

Semen-induced inflammation is another possible cause for IISE that has never been properly assessed in human reproductive medicine. In several animal species however, a transient post-mating uterine inflammation, triggered by semen components, is considered physiological [89-91]. It becomes pathological in case of inflammatory disequilibrium in favor of pro-inflammation, which is demonstrated to cause persistent endometritis, correlated with decreased fertility, requiring treatment like immuno-stimulants and corticosteroids 
[92]. In humans, the only acknowledged form of semen-induced inflammation is semen allergy, a rare and most likely underrated condition, poorly known by practitioners and thus, poorly investigated [93-96].

Furthermore, endometrial polyp (EP) is an anatomo-clinical entity that appears strongly related to IISE. It is a benign hyperplastic overgrowth of endometrial glands and stroma affecting $7.8 \%$ to $50 \%$ of women, with a prevalence of malignancy ranging from 1 to $3 \%$, particularly in post-menopausal patients [97-103]. Spontaneous regression has been reported in 6.3 to $25 \%$ of cases $[97,104]$. Although its etiopathogenesis is still unknown, it is usually presented as a hormone-related condition [103, 105, 106]. Yet, there is to date sufficient evidence indicating an inflammation-mediated pathogenesis, especially as hormonal imbalances are demonstrated to interfere with the inflammatory state of the endometrium $[65,99,106]$. Risk factors for EP are those for chronic inflammation: increasing age, menopause, obesity and hypertension [99, 102]. Higher prevalence of EP has been reported in women with diabetes mellitus [107-109], adenomyosis [110], endometriosis [111] and CE [112, 113]. In addition, studies have demonstrated increased expression of transforming growth factor 1 (TGF- 1) and vascular endothelial growth factor (VEGF) in EP [101, 113, 114]. Both are important pro-inflammatory mediators identified in many chronic inflammatory diseases [115-120]. The prevalence of EP in patients with IUD does not seem to have been assessed. Meanwhile, studies have reported cases for ParaGard copper and levonorgestrel IUD [121], despite therapeutic properties of this latter on endometrial hyperplasia [122]. The causal relationship between EP and infertility has been confirmed in only one randomized trial [102]. The acknowledged explanation is that EPs cause endometrial inflammation and sometimes constitute a mechanical barrier to sperm transportation or embryo implantation [102, 103, 105]. Current evidence rather indicates EP as an inflammation-mediated neo-process, subsequently maintaining the inflammatory state. This vicious circle partially explains why resection of EP is associated with increased rates of pregnancy in infertile women [100, 102].

Very importantly, gynecological malignancies, mainly cervical and endometrial ones, have also been demonstrated to be related to chronic inflammation, be it mediated by infectious or non-infectious conditions $[17,69,70,123]$. This highlights the long-term importance of proper diagnosis and management of chronic inflammation.

\section{IISE assessment and management: future perspectives}

To date, there are no guidelines allowing proper assessment or management of endometrial inflam- mation. Elaborating clinical scores to assess the global inflammatory risk for patients appears pertinent. The patient's clinical assessment should consider: her age, lifestyle, body mass index, blood pressure, atopy, stress factor, chronic inflammation signs, as well as a medical history of inflammation-mediated diseases and abnormal placentation-related disorders. Hysteroscopy should be scheduled during proliferative phase, as inflammation-hallmarks are the poorest at this stage.

Acute inflammation signs suggest either a transient or a persistent IISE. Absence of signs should not exclude persistent IISE as it is normally macroscopically silent. If semen-allergy is suspected, introducing the concept of "post coital hysteroscopy" appears relevant and remains to define in order to assess post-coital inflammation both macroscopically (redness, edema) and microscopically (assessment of mast-cells and eosinophils' distribution). More attention has to be given to micro-hysteroscopy as it already defines vascular patterns for the endometrium [124]. Further research is highly needed, also for histopathology that should be revised and based on normal and impaired inflammatory patterns, and performed by trained pathologists. Despite its cost, the superiority of immunohistochemistry is indisputable as it allows a better identification of the positively stained cells for all antigens [52].

The optimal inflammatory balance allowing a proper implantation and progression of a healthy pregnancy seems quite delicate. In fact, spontaneous resolution of reproductive issues may occur without any medication. This highlights the importance of a healthy lifestyle, such as weight loss, controlling metabolic diseases, exercise and/or reduced stress.

Etiologic context must be targeted whenever possible. Anti-inflammatory therapy has to be considered as well. There is increasing evidence about its effectiveness in animal models for instance $[19,92]$. In humans, several authors stress the necessity of introducing effective therapies capable of modulating the immune endometrial reproductive functions [30, 45, 80-82, 85]. In order to restore the normal endometrial inflammatory balance, minimal effective doses of pro-resolving anti-inflammatory drugs appear more relevant.

Although anti-inflammatory therapy has poorly been considered in the management of impaired endometrial inflammation, there is suggestive data highlighting the benefits of some molecules, such as lowdose acetylsalicylic acid (ASA). Its mechanism of action in the prevention of preeclampsia has never been elucidated [125] although there is evidence demonstrating its pro-resolving anti-inflammatory effect $[22,126]$. Depending on the modalities of prescription, encouraging outcomes were reported regarding perinatal death, preeclampsia, fetal growth, preterm birth and fecundability [125, 127-129]. Furthermore, it is very often well-tolerated by women, fetuses and neonates [130]. 
Corticosteroids' pro-resolving anti-inflammatory properties are widely demonstrated as well $[67,131$ 133]. Positive live birth outcomes in unexplained infertility and idiopathic recurrent miscarriage were obtained with low (or medium) dose of dexamethasone, prednisolone or prednisone, yet with low evidence level [67, 132, 134, 135]. Nevertheless, many adverse maternal and fetal effects were reported in the studies where corticosteroids were administered at high doses [45, 136]. Moreover, other molecules need to be assessed such as non-steroid-anti-inflammatory drugs (NSAIDs), whose prolonged prescription could oppose to follicle rupture though [137]. Prostaglandin E2 inhibitors have already been suggested to decrease the inflammatory environment caused by endometriosis and thus enhance endometrial receptivity for improved implantation [138]; metformin and dehydroepiandrosterone (DHEA), have been found to have anti-inflammatory properties [135, 139, 140]. Finally low-dose heparin, used in antiphospholipid autoimmune syndrome, has shown safe and effective anti-inflammatory properties in addition to its anticoagulant effect [141, 142].

\section{Conclusions}

Endometrial inflammation is a complex key-part of the endometrial physiology, regulated by a fine-regulated balance between pro-inflammatory and pro-resolving mechanisms, and involved in all reproductive events.

Infectious agents should no longer be considered as the only disturbing agent causing IISE. Any condition interfering with the immune system could result in a transient, repeated or persistent IISE. The latter could display very poor clinical and paraclinical signs. Optimal diagnostic and therapeutic tools remain to determine, yet, minimal effective doses of inflammation-pro-resolving therapies appear promising. Further research is needed for a better assessment of the inflammatory pathways involved in the reproductive tract, as well as the hysteroscopic and pathological patterns of normal and impaired endometrium, in order to improve prevention, diagnosis and treatment of obstetric and gynecological disorders.

\section{Disclosure}

The authors report no conflict of interest.

\section{References}

1. Medzhitov R. Origin and physiological roles of inflammation. Nature 2008; 454: 428-435.

2. Ashley N, Weil Z, Nelson R. Inflammation: Mechanisms, Costs, and Natural Variation. Annu Rev Ecol Evol Syst 2012; 43: 385-406.

3. Chen L, Deng H, Cui H, et al. Inflammatory responses and inflammationassociated diseases in organs. Oncotarget 2018; 9: 7204-7218.
4. Hartemann-Heurtier A, Deybach C. Artériopathie oblitérante des membres inférieurs et diabète sucré. Sang Thrombose Vaisseaux. 2004; 16 : 393-402.

5. Pahwa R, Jialal I. Chronic inflammation. StatPearls Publishing. https:// www.ncbi.nlm.nih.gov/books/NBK493173/.

6. Barnes P. Pathophysiology of allergic inflammation. Immunol Rev 2011; 242: 31-50.

7. Bianchi M. DAMPs, PAMPs and alarmins: all we need to know about danger. J Leukoc Biol 2007; 81: 1-5.

8. Herwald H, Egesten A. On PAMPs and DAMPs. J Innate Immun 2016; 8: 427-428.

9. Rai V, Agrawal DK. The role of damage- and pathogen-associated molecular patterns in inflammation-mediated vulnerability of atherosclerotic plaques. Can J Physiol Pharmacol 2017; 95: 1245-1253.

10. Chaplin D. Overview of the immune response. J Allergy Clin Immunol 2010; 125: S3-23.

11. Weiss G, Goldsmith LT, Taylor RN, et al. Inflammation in reproductive disorders. Reprod Sci 2009; 16: 216-229.

12. Tang D, Kang R, Coyne CB, et al. PAMPs and DAMPs: signal Os that spur autophagy and immunity. Immunol Rev 2012; 249: 158-175.

13. Masouris I, Klein M, Dyckhoff S, et al. Inhibition of DAMP signaling as an effective adjunctive treatment strategy in pneumococcal meningitis. J Neuroinflammation 2017; 14: 214.

14. Janeway CJ, Travers P, Walport M. Principles of innate and adaptive immunity. In: Janeway CA Jr, Travers P, Walport M, Shlomchik M (eds.), Immunobiology: The Immune System in Health and Disease ( $5^{\text {th }}$ ed.). Garland Science Taylor \& Francis, Inc., New York 2001.

15. den Haan JM, Arens R, van Zelm MC. The activation of the adaptive immune system: cross-talk between antigen-presenting cells, $T$ cells and B cells. Immunol Lett 2014; 162: 103-112.

16. Institute for Quality and Efficiency in Health Care (IQWiG). The innate and adaptive immune systems. InformedHealth.org [Internet], 2006. https://www.ncbi.nlm.nih.gov/books/NBK279396/.

17. Jabbour H, Sales K, Catalano R, Norman J. Inflammatory pathways in female reproductive health and disease. Focus on Vascular Function in Female Reproduction. Reproduction 2009; 138: 903-919.

18. Serhan CN, Brain SD, Buckley CD, et al. Resolution of inflammation: state of the art, definitions and terms. FASEB J. 2007; 21: 325-332.

19. Serhan C, Chiang N, van Dyke T. Resolving inflammation: dual anti-inflammatory and proresolution lipid mediators. Nat Rev Immunol 2008; 8: 349-361.

20. Lawrence T, Gilroy DW. Chronic inflammation: a failure of resolution? Int J Exp Pathol 2007; 88: 85-94.

21. Serhan CN, Petasis NA. Resolvins and protectins in inflammation resolution. Chem Rev 2011; 111: 5922-5943.

22. Sugimoto MA, Sousa LP, Pinho V, et al. Resolution of Inflammation: What Controls Its Onset? Front Immunol 2016; 7: 160.

23. Kumar V, Abbas A, Fausto N, Aster J. Pathologic basis of disease ( $8^{\text {th }}$ ed.). Saunders, Philadelphia 2010.

24. Medzhitov R. Inflammation 2010: new adventures of an old flame. Cell 2010; 140: 771-776.

25. Garn H, Bahn S, Baune BT, et al. Current concepts in chronic inflammatory diseases: Interactions between microbes, cellular metabolism, and inflammation. J Allergy Clin Immunol 2016; 138: 47-56.

26. Birben E, Sahiner UM, Sackesen C, et al. Oxidative stress and antioxidant defense. World Allergy Organ J 2012; 5: 9-19.

27. Andersen C, Murphy K, Fernandez M. Impact of Obesity and Metabolic Syndrome on Immunity. Adv Nutr 2016; 7: 66-75.

28. [Editorial]. A current view on inflammation. Evolving mechanistic and conceptual understanding of inflammation drives insight into human disease and new approaches for therapy. Nat Immunol 2017; 18: 825.

29. Nair A, Taylor H. The Mechanism of Menstruation. In: Amenorrhea: A case-Based, Clinical Guide, Santoro NF, Neal-Perry G (eds.). Springer Science + Business Media, New-York 2010: 21-34.

30. Maybinand J, Critchley H. Menstrual physiology: implications for endometrial pathology and beyond. Human Reprod Update 2015; 21: 748761.

31. Bulmer JN, Morrison L, Longfellow M, et al. Granulated lymphocytes in human endometrium: histochemical and immunohistochemical studies. Hum Reprod 1991; 6: 791-798. 
32. Jones RK, Bulmer JN, Searle RF. Phenotypic and functional studies of leukocytes in human endometrium and endometriosis. Hum Reprod Update 1998; 4: 702-709.

33. Lee JY, Lee M, Lee SK. Role of endometrial immune cells in implantation. Clin Exp Reprod Med 2011; 38: 119-125.

34. Faas MM, de Vos P. Uterine NK cells and macrophages in pregnancy. Placenta 2017; 56: 44-52.

35. Bashiri A, Halper K, Orvieto R. Recurrent Implantation Failure-update overview on etiology, diagnosis, treatment and future directions. Reprod Biol Endocrinol 2018; 16: 121.

36. Wahab M, Thompson J, Al-Azzawi F. The distribution of endometrial leukocytes and their proliferation markers in trimegestone-treated postmenopausal women compared to the endometrium of the natural cycle: a dose-ranging study. Hum Reprod 1999; 14: 1201-1206.

37. Armstrong G, Maybin J, Murray A, et al. Endometrial apoptosis and neutrophil infiltration during menstruation exhibits spatial and temporal dynamics that are recapitulated in a mouse model. Sci Rep 2017; 7: 17416.

38. Biswas Shivhare S, Bulmer JN, Innes BA, et al. Menstrual cycle distribution of uterine natural killer cells is altered in heavy menstrual bleeding. J Reprod Immunol 2015; 112: 88-94.

39. Kitaya K, Yasuda J, Yagi I, et al. IL-15 expression at human endometrium and decidua. Biol Reprod 2000; 63: 683-687.

40. Kodama T, Hara T, Okamoto E, et al. Characteristic changes of large granular lymphocytes that strongly express CD56 in endometrium during the menstrual cycle and early pregnancy. Hum Reprod 1998; 13 : 1036-1043.

41. Jabbour HN, Sales KJ, Smith OP, et al. Prostaglandin receptors are mediators of vascular function in endometrial pathologies. Mol Cell Endocrinol 2006; 252: 191-200.

42. Jabbour HN, Sales KJ. Prostaglandin receptor signalling and function in human endometrial pathology. Trends Endocrinol Metab 2004; 15: 398 404.

43. Trenti A, Tedesco S, Boscaro C, et al. Estrogen, Angiogenesis, Immunity and Cell Metabolism: Solving the Puzzle. Int J Mol Sci. 2018; 19: 859.

44. Giannoni E, Guignard L, Knaup Reymond M, et al. Estradiol and progesterone strongly inhibit the innate immune response of mononuclear cells in newborns. Infect Immun 2011; 79: 2690-2698.

45. Roberston S, Jin M, Yu D, et al. Corticosteroid therapy in assisted reproduction - immune suppression is a faulty premise. Hum Reprod 2016 31: 2164-2173.

46. Munro MG, Critchley HO, Broder MS, et al. FIGO classification system (PALM-COEIN) for causes of abnormal uterine bleeding in nongravid women of reproductive age. Int J Gynaecol Obstet 2011; 113: 3-13.

47. Munro MG, Critchley HOD, Fraser IS, Committee FMD. The two FIGO systems for normal and abnormal uterine bleeding symptoms and classification of causes of abnormal uterine bleeding in the reproductive years: 2018 revisions. Int J Gynaecol Obstet 2018; 143: 393-408.

48. Wouts M, Duisterhout J, Kuik D, Schoemaker J. The chance of spontaneous conception for the infertile couple referred to an academic clinic for reproductive endocrinology and fertility in The Netherlands. Eur J Obstet Gynecol Reprod Biol 1987; 26: 243-250.

49. Moreno I, Cicinelli E, Garcia-Grau I, et al. The diagnosis of chronic endometritis in infertile asymptomatic women: a comparative study of histology, microbial cultures, hysteroscopy, and molecular microbiology. Am J Obstet Gynecol 2018; 218: 602.e1-e16.

50. Park HJ, Kim YS, Yoon TK, Lee WS. Chronic endometritis and infertility. Clin Exp Reprod Med 2016; 43 (Suppl. 4): 185-192.

51. Di Spiezio Sardo A, Palma F, Calagna G, et al. Chronic Endometritis. In: Genital Infections and Infertility. IntechOpen http://dx.doi. org/10.5772/63023.

52. Chen YQ, Fang RL, Luo YN, Luo CQ. Analysis of the diagnostic value of CD138 for chronic endometritis, the risk factors for the pathogenesis of chronic endometritis and the effect of chronic endometritis on pregnancy: a cohort study. BMC Womens Health 2016; 16: 60.

53. Cicinelli E, Vitagliano A, Kumar A, et al. Unified diagnostic criteria for chronic endometritis at fluid hysteroscopy: proposal and reliability evaluation through an international randomized-controlled observer study. Fertil Steril 2019; 112: 162-73.e2.
54. Puente E, Alonso L, Laganà AS, et al. Chronic Endometritis: Old Problem, Novel Insights and Future Challenges. Int J Fertil Steril 2020; 13 250-256.

55. Cicinelli E, Resta L, Nicoletti R, et al. Endometrial micropolyps at fluid hysteroscopy suggest the existence of chronic endometritis. Hum Reprod 2005; 20: 1386-1389.

56. Cicinelli E, de Ziegler D, Nicoletti R, et al. Chronic endometritis: correlation among hysteroscopic, histologic, and bacteriologic findings in a prospective trial with 2190 consecutive office hysteroscopies. Fertil Steril 2008; 89: 677-684.

57. Song D, Li TC, Zhang Y, et al. Correlation between hysteroscopy findings and chronic endometritis. Fertil Steril 2019; 111: 772-779.

58. Cicinelli E, Matteo M, Trojano G, et al. Chronic endometritis in patients with unexplained infertility: Prevalence and effects of antibiotic treatment on spontaneous conception. Am J Reprod Immunol 2018; 79 e12782.

59. Cicinelli E, Matteo M, Tinelli R, et al. Chronic endometritis due to common bacteria is prevalent in women with recurrent miscarriage as confirmed by improved pregnancy outcome after antibiotic treatment. Reprod Sci 2014; 21: 640-647.

60. Zhu L, Luo F, Hu W, et al. Bacterial communities in the womb during healthy pregnancy. Front Microbiol 2018; 9: 2163.

61. Kitaya K, Nagai Y, Arai W, et al. Characterization of microbiota in endometrial fluid and vaginal secretions in infertile women with repeated implantation failure. Mediators Inflamm 2019; 2019: 4893437

62. Cicinelli E, Trojano G, Mastromauro M, et al. Higher prevalence of chronic endometritis in women with endometriosis: a possible etiopathogenetic link. Fertil Steril 2017; 108: 289-95.e1.

63. de Ziegler D, Pirtea P, Galliano D, et al. Optimal uterine anatomy and physiology necessary for normal implantation and placentation. Fertil Steril 2016; 105: 844-854.

64. Tamura H, Kishi H, Kitade M, et al. Complications and outcomes of pregnant women with adenomyosis in Japan. Reprod Med Biol 2017; 16 330-336

65. Carp HJ, Selmi C, Shoenfeld Y. The autoimmune bases of infertility and pregnancy loss. J Autoimmun 2012; 38: J266-274.

66. Laird SM, Tuckerman EM, Cork BA, et al. A review of immune cells and molecules in women with recurrent miscarriage. Hum Reprod Update 2003; 9: 163-174.

67. Kemp MW, Newnham JP, Challis JG, et al. The clinical use of corticosteroids in pregnancy. Hum Reprod Update 2016; 22: 240-259.

68. ACOG Committee opinion $N^{\circ} 743$. Low-dose aspirin use during pregnancy. Obstet Gynecol 2018; 132: e44-52.

69. Goswami B, Rajappa M, Sharma M, Sharma A. Inflammation: its role and interplay in the development of cancer, with special focus on gynecological malignancies. Int J Gynecol Cancer 2008; 18: 591-599.

70. Gitas G, Proppe L, Alkatout I, et al. Accuracy of frozen section at early clinical stage of endometrioid endometrial cancer: a retrospective analysis in Germany. Arch Gynecol Obstet 2019; 300: 169-174.

71. Livshits A, Seidman D. Fertility issues in women with diabetes. Womens Health (Lond) 2009; 5: 701-707.

72. Chakrabarti S, Chowdhury S, Ghosh S, et al. Stillbirth and miscarriage associated with type 2 diabetes mellitus. Int J Res Dev Pharm L Sci 2015; 4: 1732-1736

73. Jonasson J, Brismar K, Sparen P, et al. Fertility in Women With Type 1 Diabetes. A population-based cohort study in Sweden. Diabetes Care 2007; 30: 2271-2276.

74. Porpora M, Lucchini R, Abballe A, et al. Placental transfer of persistent organic pollutants: a preliminary study on mother-newborn pairs. Int J Environ Res Public Health 2013; 10: 699-711.

75. Kelly F, Fussell J. Linking ambient particulate matter pollution effects with oxidative biology and immune responses. Ann N Y Acad Sci 2015; 1340: 84-94.

76. Ruder E, Hartman T, Goldman M. Impact of oxidative stress on female fertility. Curr Opin Obstet Gynecol 2009; 21: 219-222.

77. Agarwal A, Aponte-Mellado A, Premkumar B, et al. The effects of oxidative stress on female reproduction: a review. Reprod Biol Endocrinol 2012; 10: 49.

78. Arck P, Hansen P, Mulac Jericevic B, et al. Progesterone during pregnancy: endocrine-immune cross talk in mammalian species and the role of stress. Am J Reprod Immunol 2007; 58: 268-279. 
79. Nakamura K, Sheps S, Arck P. Stress and reproductive failure: past notions, present insights and future directions. J Assist Reprod Genet 2008; 25: 47-62.

80. Kyama C, Debrock S, Mwenda J, D'Hooghe T. Potential involvement of the immune system in the development of endometriosis. Reprod Biol Endocrinol 2003; 1: 123.

81. Miller J, Ahn S, Monsanto S, et al. Implications of immune dysfunction on endometriosis associated infertility. Oncotarget 2016; 8: 7138 7147.

82. Jiang L, Yan Y, Liu Z, Wang Y. Inflammation and endometriosis. Front Biosci (Landmark Ed) 2016; 21: 941-948.

83. Vallvé-Juanico J, Houshdaran S, Giudice LC. The endometrial immune environment of women with endometriosis. Hum Reprod Update 2019; 25: 564-591.

84. Laganà AS, Garzon S, Götte M, et al. The Pathogenesis of Endometriosis: Molecular and Cell Biology Insights. Int J Mol Sci 2019; 20: 5615.

85. Carrarelli P, Yen C, Funghi I, et al. Expression of Inflammatory and Neurogenic Mediators in Adenomyosis. Reprod Sci 2017; 24: 369-375.

86. Harada T, Khine Y, Kaponis A, et al. The Impact of Adenomyosis on Women's Fertility. Obstet Gynecol Surv 2016; 71: 557-568.

87. Dueholm M. Uterine adenomyosis and infertility, review of reproductive outcome after in vitro fertilization and surgery. Acta Obstetr Gynecol Scand 2017; 96: 715-726.

88. Stanekova V, Woodman R, Tremellen K. The rate of euploid miscarriage is increased in the setting of adenomyosis. Hum Reprod Open 2018; 3: hoy011.

89. Troedsson M. Mating-induced endometritis: Physiology or pathology? Vet J 2014; 199: 9-10.

90. Christoffersen M, Troedsson M. Inflammation and fertility in the mare. Reprod Domest Anim 2017; 52: 14-20.

91. England G, Burgess C, Freeman S. Perturbed sperm-epithelial interaction in bitches with mating-induced endometritis. Vet J 2012; 194 314-318.

92. Maischberger E, Irwin J, Carrington S, Duggan V. Equine post-breeding endometritis: A review. Ir Vet J 2008; 61: 163-168.

93. Song W, Kim D, Kim M. Human seminal plasma allergy: successful pregnancy after prophylactic anti-histamine treatment. Asia Pac Allergy 2011; 1: 168-171.

94. Mike N, Bird G, Asquith P. A new manifestation of seminal fluid hypersensitivity. Q J Med 1990; 75: 371-376.

95. Nist G, von den Driesch P. Human seminal plasma allergy - a rare cause of recurrent anaphylaxis. J Dtsch Dermatol Ges 2007; 5: 34-36.

96. Bernstein J, Sugumaran R, Bernstein D, Bernstein I. Prevalence of human seminal plasma hypersensitivity among symptomatic women Ann Allergy Asthma Immunol 1997; 78: 54-58.

97. Lieng M, Istre O, Sandvik L, Qvigstad E. Prevalence, 1-year regression rate, and clinical significance of asymptomatic endometrial polyps: cross-sectional study. J Minim Invasive Gynecol 2009; 16: 465-471.

98. Unal B, Doğan S, Karaveli F, et al. Giant endometrial polyp in a postmenopausal woman without hormone/drug use and vaginal bleeding. Case Rep Obstet Gynecol 2014; 2014: 518398.

99. Lieng M. Endometrial Polyps, 2015. http://www.nfog.org/files/guidelines/NFOG Guideline NOR_160419\%20Endometrial\%20polyp\%20 NO\%20merged.pdf

100. Zhang H, He X, Tian W, Song X. Hysteroscopic resection of endometrial polyps and Assisted Reproductive Technology pregnancy outcomes compared with no treatment: a systematic review. J Minim Invasive Gynecol 2019; 26 (Suppl. 4): 618-627.

101. Haque M, Mneimneh W. Endometrial polyp. PathologyOutlines.com 2018. http://www.pathologyoutlines.com/topic/uterusendopolyp. htm

102. American Association of Gynecologic Laparoscopists. AAGL practice report: practice guidelines for the diagnosis and management of endometrial polyps. J Minim Invasive Gynecol 2012; 19: 3-10.

103. Szeszko Ł, Oszukowski P, Kisiel A, et al. Histopathological results analysis in women undergoing hysteroscopic procedures due to endometrial polyps. Health Prob Civil 2019; 13: 99-103.

104. Wong M, Crnobrnja B, Liberale V, et al. The natural history of endome trial polyps. Hum Reprod 2017; 32: 340-345.
105. Pereira N, Petrini AC, Lekovich JP, et al. Surgical Management of Endometrial Polyps in Infertile Women: A Comprehensive Review. Surg Res Pract 2015; 2015: 914390.

106. Kanthi JM, Remadevi C, Sumathy S, et al. Clinical Study of Endometrial Polyp and Role of Diagnostic Hysteroscopy and Blind Avulsion of Polyp. J Clin Diagn Res 2016; 10: QC01-4.

107. Hassa H, Korkmazer E, Tokgöz V, Öge T. Independent risk factors for endometrial polyps: diabetes, hypertension, and obesity. Asian Pac J Reprod 2012; 1: 312-4

108. Serhat E, Cogendez E, Asoglu M, et al. Is there a relationship between endometrial polyps and obesity, diabetes mellitus, hypertension? Arch Gynecol Obstet 2014; 290: 937-941.

109. Nappi L, Indraccolo U, Di Spiezio Sardo A, et al. Are diabetes, hypertension, and obesity independent risk factors for endometrial polyps? J Minim Invasive Gynecol 2009; 16: 157-162.

110. Indraccolo U, Barbieri F. Relationship between adenomyosis and uterine polyps. Eur J Obstet Gynecol Reprod Biol 2011; 157: 185-189.

111. Zheng QM, Mao HI, Zhao YJ, et al. Risk of endometrial polyps in women with endometriosis: a meta-analysis. Reprod Biol Endocrinol 2015; 13: 103.

112. Carvahlo F, Aquiar F, Tomioka R, et al. Functional endometrial polyps in infertile asymptomatic patients: a possible evolution of vascular changes secondary to endometritis. Eur J Obstet Gynecol Reprod Biol 2013; 170: 152-156.

113. Kim K, Peng R, Ro Y, Robboy S. A diagnostically useful histopathologic feature of endometrial polyp: the long axis of endometrial glands arranged parallel to surface epithelium. Am J Surg Pathol 2004; 28 : 1057-1062.

114. Resta L, Cicinelli E, Lettini T, et al. Possible Inflammatory Origin of Endometrial Polyps. Arch Reprod Med Sexual Health 2018; 1: 8-16.

115. Kajdaniuk D, Marek B, Borgiel-Marek H, Kos-Kudla B. Transforming growth factor 1 (TGF 1) in physiology and pathology. Endokrynol Pol 2013; 64: 384-396.

116. Han G, Li F, Singh T, et al. The Pro-inflammatory Role of TGF 1: A Paradox? Int J Biol Sci 2012; 8: 228-235.

117. Sauty A, Aubert J. Le Transforming Growth Factor-beta (TGF-): une cytokine de plus en plus impliquée dans la physiopathogénie des maladies pulmonaires, fibroses en particulier. Revue des Maladies Respiratoires 2005; 22: 11-19.

118. Guadagni F, Ferroni P, Palmirotta R, et al. Review. TNF/VEGF cross-talk in chronic inflammation-related cancer initiation and progression: an early target in anticancer therapeutic strategy. In Vivo 2007; 21: 147161.

119. Kirk SL, Karlik SJ. VEGF and vascular changes in chronic neuroinflammation. J Autoimmun 2003; 21: 353-363.

120. Afuwape A, Kiriakidis S, Paleolog E. The role of the angiogenic molecule VEGF in the pathogenesis of rheumatoid arthritis. Histol Histopathol 2002; 17: 961-972.

121. Brechin S, Cameron S, Paterson A, et al. Intrauterine polyps - a cause of unscheduled bleeding in women using the levonorgestrel intra uterine system. Hum Reprod 2000; 15: 650-652.

122. Arnes M, Hvingel B, Orbo A. Levonorgestrel-impregnated Intrauterine device reduces occurrence of hyperplastic polyps: a population-based follow-up cohort study. Anticancer Res 2014; 34: 2319-2324.

123. Gitas G, Ertan K, Rody A, et al. Papillary squamotransitional cell carcinoma of the uterine cervix: a case report and review of the literature. J Med Case Rep 2019; 13: 319.

124. van Herendael BJ, Stevens MJ, Flakiewicz-Kula A, Hansch C. Dating of the endometrium by microhysteroscopy. Gynecol Obstet Invest. 1987; 24: 114-118.

125. Roberge S, Nicolaides KH, Demers S, et al. Prevention of perinatal death and adverse perinatal outcome using low-dose aspirin: a metaanalysis. Ultrasound Obstet Gynecol 2013; 41: 491-499.

126. Morris T, Stables M, Hobbs A, et al. Effects of low-dose aspirin on acute inflammatory responses in humans. J Immunol 2009; 183: 2089-2096.

127. Schisterman EF, Silver RM, Lesher LL, et al. Preconception low-dose aspirin and pregnancy outcomes: results from the EAGeR randomised trial. Lancet 2014; 384: 29-36. 
128. Leitich $\mathrm{H}$, Egarter $\mathrm{C}$, Husslein $\mathrm{P}$, et al. A meta-analysis of low dose aspirin for the prevention of intrauterine growth retardation. Br J Obstet Gynaecol 1997; 104: 450-459.

129. Emeagi J, Patni S, Tikum H, Mander A. Low dose aspirin for preventing and treating pre-eclampsia. Author of editorial did not criticise studies' methodology. BMJ 1999; 319: 316.

130. Ahrens KA, Silver RM, Mumford SL, et al. Complications and Safety of Preconception Low-Dose Aspirin Among Women With Prior Pregnancy Losses. Obstet Gynecol 2016; 127: 689-698.

131. Yubero S, Ramudo L, Manso MA, De Dios I. Mechanisms of dexamethasone-mediated chemokine down-regulation in mild and severe acute pancreatitis. Biochim Biophys Acta 2009; 1792: 1205-1211.

132. Buttgereit F, da Silva JA, Boers M, et al. Standardised nomenclature for glucocorticoid dosages and glucocorticoid treatment regimens: current questions and tentative answers in rheumatology. Ann Rheum Dis 2002; 61: 718-722.

133. Gupta P, Bhatia V. Corticosteroid Physiology and Principles of Therapy Indian J Pediatr 2008; 75: 1039-1044.

134. Moradan S, Ghorbani R. Dexamethasone in unexplained infertility. Saudi Med J 2009; 30: 1034-1036.

135. Beck I, Boothroyd C, Proctor M, Hughes E. Oral anti-oestrogens and medical adjuncts for subfertility associated with anovulation. Cochrane Database Syst Rev 2005; 2005: CD002249.

136. Namdar Ahmadabad H, Kayvan Jafari S, Nezafat Firizi M, et al. Pregnancy outcomes following the administration of high doses of dexamethasone in early pregnancy. Clin Exp Reprod Med 2016; 43: 15-25.

137. Gaytán M, Morales C, Bellido C, et al. Non-steroidal anti-inflammatory drugs (NSAIDs) and ovulation: lessons from morphology. Histol Histopathol 2006; 21: 541-556.

138. Lin $\mathrm{YH}$, Chen $\mathrm{YH}$, Chang HY, et al. Chronic Niche Inflammation in Endometriosis-Associated Infertility: Current Understanding and Future Therapeutic Strategies. Int J Mol Sci 2018; 19: 2385.

139. Lichte P, Pfeifer R, Werner B, et al. Dehydroepiandrosterone modulates the inflammatory response in a bilateral femoral shaft fracture model. Eur J Med Res 2014; 19: 27

140. Straub RH, Schölmerich J, Zietz B. Replacement therapy with DHEA plus corticosteroids in patients with chronic inflammatory diseasessubstitutes of adrenal and sex hormones. Z Rheumatol 2000; 59: 108-118.

141. Mousavi S, Moradi M, Khorshidahmad T, Motamedi M. Anti-Inflammatory Effects of Heparin and Its Derivatives: A Systematic Review. Adv Pharmacol Sci 2015; 2015: 507151

142. Downing LJ, Strieter RM, Kadell AM, et al. Low-dose low-molecularweight heparin is anti-inflammatory during venous thrombosis. J Vasc Surg 1998; 28: 848-854 